\title{
La investigación en Tecnología Educativa en un contexto digital
}

\author{
Mercè Gisbert Cervera \\ Universitat Rovira I Virgili \\ merce.gisbert@urv.cat
}

La economía del conocimiento y la sociedad de la información aportan la necesidad de nuevas habilidades técnicas y cognitivas que nos permitan resolver problemas y situaciones en nuevos ambientes. Se ha argumentado que no es sólo una cuestión de mantenerse al día con técnicas específicas, también es importante volver a pensar las competencias básicas clave para que podamos adaptarnos a esta sociedad en constante cambio (Griffin et al., 2012; FIET ${ }^{1}$, 2014).

En una sociedad, cada vez más compleja y más imprevisible que se caracteriza por lo que Bauman (2003) denominó como "modernidad liquida" considerándola como una época llena de oportunidades y peligros, uno de nuestros retos será aprovechar las oportunidades y ser capaces de contrarrestar los peligros. Coincidimos con Davis (2013) en que es realmente una época paradójica y llena de contrasentidos puesto que la necesidad que el individuo tiene de relacionarse se ve amenazada de manera constante por la presencia del "otro" del mismo modo que la esperanza de seguridad colectiva y de unión se ve amenazadas por los deseos de libertad y de elección individuales. En este sentido, lo individual y lo colectivo se difuminan en una realidad en continuo cambio, efímera y difícil de prever que cada vez hace más difícil la tarea, no sólo de definir unos escenarios estables en los que diseñar y desarrollar el proceso educativo, sino también definir cuáles son los contenidos y las competencias clave para la formación de la ciudadanía y de los profesionales que demandará en un futuro próximo.

El mundo también ha cambiado de referentes contextuales. Si bien es cierto que, principalmente en los primeros niveles del sistema educativo, es fundamental tener referentes próximos no podemos olvidar que vivimos en un mundo global del que debemos conocer las claves para poder interpretarlo pues constituye un importante marco de referencia personal, educativo y social. A partir de la idea de tener una visión del mundo global pero no perder los referentes cercanos en 1980, y aplicado a la economía, aparece por primera vez esta idea. Idea que define Roberson (2003) denominándola Glocalización para referirse a la supresión de fronteras entre lo político, lo económico y lo socio-cultural. Una visión global del mundo no tiene por qué ser incompatible con la consideración de la identidad local que es la que ha de permitir abordar la construcción la de democracia y de la sociedad desde otras propuestas (Gairín, 2011) y que, en cierto modo, debe constituir uno de los pilares de la educación básica obligatoria.

En este sentido, es fundamental abordar desde la investigación, y de una manera crítica, el triángulo contenido-contenedor-contexto para poder obtener resultados que puedan facilitar a la

\footnotetext{
${ }^{1}$ Fórum Internacional de Educación y Tecnología que se celebró en la Universitat Rovira i Virgili en Tarragona en el mes de junio de 2014.
} 
ciudadanía, en general, y al sistema educativo, en particular, suficientes herramientas tecnológicas para que puedan convertirse en ciudadanos digitales críticos con criterio, no sólo tecnológico, para poder distinguir lo verdadero de lo falso a la vez que asumen la responsabilidad y las oportunidades que hay detrás de este concepto (Cobo, 2016). Sin ninguna duda, este es y será uno de los mayores retos de la educación, en general, y de los sistemas escolares en particular. Formar y capacitar a ciudadanos que sean capaces de conocer y valorar su contexto próximo (local) a la vez que ser lo suficientemente flexibles para comprender un mundo global construido sobre redes tecnológicas y sociales que tienen sus propias reglas, amenazas y oportunidades que evolucionan y cambian de manera permanente y constante. Por primera vez en la historia de la educación, el contexto externo tiene más capacidad de influencia que el propio entorno escolar y éste, con su modelo actual, cada vez tiene más dificultades para responder a los retos de la sociedad digital.

El desarrollo de políticas que aseguren la alfabetización digital, que promuevan la inclusión y la participación de la ciudadanía, más allá del puro consumo, así como los derechos de propiedad intelectual para preservar la autoría del conocimiento fueron algunas de las recomendaciones del FIET (2014) para los poderes públicos que deben ir acompañadas de estrategias y planes de acción para poder asegurar su desarrollo. Recomendaciones sobre las que (Carrera et al., 2016) trabajan y a las que añaden la formación en el uso responsable, ético y seguro de la tecnología, así como el compromiso individual y colectivo en el uso responsable de los recursos tecnológicos.

La producción del conocimiento, el desarrollo de contenidos, los escenarios especializados para enseñar y aprender los tiempos y espacios educativos el rol de los profesores y de los estudiantes, ... se han visto sobrepasados por el alcance de la red INTERNET y por el impacto que las tecnologías digitales han tenido, como hemos mencionado anteriormente, en la dimensión individual y social del individuo. ¿Qué pueden hacer los sistemas educativos para responder a las necesidades y expectativas de esta modernidad líquida? ¿Cuál es el rol que tiene que desarrollar la escuela en un ecosistema digital cuando ella aún es analógica? ¿Cómo conseguimos que los docentes puedan responder a las exigencias de la modernidad líquida? ¿Somos conscientes de las competencias que deberán desarrollar nuestros estudiantes en un contexto social y profesional en continua cambio y para el que no somos capaces de prever su evolución más allá de tres o cuatro años vista? ¿Serán capaces los poderes públicos de tener una visión suficiente amplia y flexible para poder definir políticas con visión de futuro? Estos son algunos de los interrogantes a los que intentaremos dar respuesta de manera teórica en los siguientes apartados de este punto a modo de fundamentación teórica del proyecto que presentamos.

Todas estas preguntas y muchas más son las que deberían asumir los jóvenes investigadores en Tecnología Educativa para poder aportar evidencias de cómo mejorar la educación desde un contexto digital. Al mismo tiempo, deben ser capaces de estructurar todos estos resultados y evidencias empíricas en forma de artículos y publicaciones que permitan su difusión y transferencia en publicaciones como ésta.

\section{REFERENCIAS BIBLIOGRÁFICAS}

Bauman, Z. (2003). Modernidad líquida. México: Fondo de Cultura Económica.

Carerra, F. Arní, R., Camps, V., y Carmona, E. (2016). Ètica i Tecnologia en Educació: una perspectiva local per a una pràctica global. En M. Gisbert y J. González (Eds.) Nous escenaris d'aprenentatge des d'una visió transformadora. Wolters Kluwer España, S.A.: Madrid. 
Cobo, C. (2016). La Innovación Pendiente: Reflexiones (y Provocaciones) sobre educación, tecnología y conocimiento. Montevideo: Penguin Random House.

Davis, M. (2013). Dialectics of time and technology in liquid modernity. Thesis Eleven, 18(1). Recuperado de: http://journals.sagepub.com/doi/full/10.1177/0725513613500268

Gairín, J. (2011). Competency-Based Training of teachers. Bordón 63(1), 93-108.

Griffin, P y Care, E. (Eds.) (2012). Assessment and Teaching of 21st Century Skills. Methods and Approach. Springer Netherlands.

Robertson, R. (2003). "Glocalización: tiempo-espacio y homogeneidad heterogeneidad». Cansancio del Leviatán: problemas políticos de la mundialización. Madrid: Trotta.

\section{INFORMACIÓN SOBRE LA AUTORA}

\section{Mercè Gisbert Cervera}

Universitat Rovira I Virgili

Doctora en Ciencias de la Educación. Profesora Catedrática de Didáctica y O. Escolar en la Universidad Rovira i Virgili. Investigadora principal del grupo de investigación ARGET de la URV. Coordinadora del Máster interuniversitario a distancia Tecnología Educativa: e-learning y Gestión del Conocimiento. Directora de la Revista UTE. Revista electrónica Universitas Tarraconensis. Revista de Ciencias de la Educación.

\section{(cc) BY-NC}

Los textos publicados en esta revista están sujetos a una licencia de Reconocimiento 4.0 España de Creative Commons. Puede copiarlos, distribuirlos, comunicarlos públicamente y hacer obras derivadas siempre que reconozca los créditos de las obras (autoría, nombre de la revista, institución editora) de la manera especificada por los autores o por la revista. La licencia completa se puede consultar en:Licencia Creative Commons Atribución-NoComercial-Compartir por igual 4.0 Internacional. 